\title{
Analysis
}

\section{How New Zealand has contained expenditure on drugs}

BMJ 2010; 340 doi: http://dx.doi.org/10.1136/bmj.c2441 (Published 18 May 2010) Cite this as: BMJ 2010;340:c2441

- Article

- Related content

- Metrics

- Responses

- Peer review

-

Jacqueline Cumming, director ${ }^{1}$, Nicholas Mays, professor of health policy 12 , Jacob Daubé, research assistant 1

\section{Author affiliations}

Correspondence to: J Cumming jackie.cumming@vuw.ac.nz

Accepted 19 April 2010

The approach of New Zealand's Pharmaceutical Management Agency (PHARMAC) has much to commend it, say Jacqueline Cumming and colleagues

The recent economic crisis has forced Western countries to examine how they contain health spending and improve value for money. Spending on drugs averages around $15 \%$ of total health spending for countries in the Organisation for Economic Cooperation and Development (OECD).1 Improved management of spending on drugs can therefore make an important contribution to containing health budgets.

In recent years, increases in drug costs in New Zealand have been below those experienced in other countries while public coverage has improved. We discuss the Pharmaceutical Management Agency's (PHARMAC) role in achieving this, its processes for setting priorities, criticisms about its work, and implications for other healthcare systems.

\section{History and role}

New Zealand's healthcare system is predominantly publicly financed from general taxation and provides all drugs free of charge for people in hospital and a comprehensive set of subsidised drugs for people receiving services outside hospital.

For many years, the rise in expenditure on community drug treatment was a major problem. During the 1980s, for example, government expenditure on non-hospital drugs grew at almost $15 \%$ a year, faster than any other component of healthcare spending.2

PHARMAC was established in June 1993 with the objective of securing the best health outcomes from community drug treatment, within the amount of funding available.3 PHARMAC's role has now expanded, and it not only manages the community drug budget but also works to ensure the optimal use of medicines; negotiates prices and supply terms for some hospital medicines; manages the basket of essential cancer drugs that must be made available to New Zealanders; and manages exceptional circumstances schemes that supply drug funding for people with rare conditions. 3 PHARMAC is governed by a government appointed but independent board accountable to the minister of health and acts on behalf of New Zealand's 20 geographically based district health boards, which plan, purchase, and provide health services. 


\section{How PHARMAC works}

Once a drug is approved for sale in New Zealand, drug companies can apply to PHARMAC for it to be government funded. PHARMAC's key roles are to decide whether a medicine will be subsidised, the price the government is prepared to pay, and conditions of access. In community settings, only drugs on PHARMAC's pharmaceutical schedule receive government funding; New Zealanders must pay for other registered medicines themselves. Patients generally make a co-payment (NZ\$3 ( $£ 1.40 ; € 1.70 ;$ US\$2.20) per item) for each medicine listed in the schedule, but they may also have to pay an additional fee if the subsidy level PHARMAC has set is less than the price charged by the drug company.

The schedule currently contains about 2000 items. PHARMAC uses a rigorous and well documented $\mathbf{5}$ process to determine which drugs are added to the national schedule, to try to ensure the best outcomes for the funding available.

When a company applies to PHARMAC for government funding for a new drug it submits information on the costs and benefits. This information is assessed by PHARMAC's pharmacology and therapeutics advisory committee, which advises whether the medicine should be subsidised, although PHARMAC is not bound to accept the committee's recommendations.

The decision whether to fund is based on nine criteria (box 1).4 The weight given to each criterion varies as PHARMAC considers appropriate. However, one of the key criteria is cost effectiveness. PHARMAC calculates incremental costs and benefits (using quality adjusted life years or QALYs) associated with new medicines compared with current and expected clinical practice, including any averted health sector costs. 6 It then prioritises new drugs against other potential expenditures, such as other new drugs or expanding access to drugs that are already funded.

\section{Box 1 PHARMAC's criteria for deciding funding4}

Health needs of all the eligible population

Particular health needs of Maori and Pacific peoples (both groups have lower health status than other New Zealanders)

Availability and sustainability of existing medicines, treatment devices, and related products

Clinical benefits and risks

Cost effectiveness of meeting health needs by funding the drug rather than using other publicly funded health and disability support services

Budgetary impact of any changes to the schedule

Direct cost to health service users

Government's priorities for health funding

Such other criteria as PHARMAC thinks fit (after appropriate consultation)

Because cost effectiveness is only one of PHARMAC's decision making criteria and because the agency must work to a variable annual budget, there is no one cost per QALY value that determines whether a medicine is subsidised. Rather the data are used to create a relative ranking of medicines that could be funded. Medicines are funded according to their place on the list along with information on the other decision criteria. Between 1998 and 2005, new investments cost on average $\$ 6900$ per QALY gained, although the patient weighted annual average cost per QALY gained ranged from $\$ 2991$ in 2001-2 to \$15 768 in 2003-4.5 
PHARMAC then uses several processes to manage the prices of medicines on the schedule. Drug companies negotiate with PHARMAC over the price and other conditions of access, encouraging competition between suppliers.7 PHARMAC uses reference pricing to set government subsidies at the same level for medicines with the same or similar effects (that is, within a therapeutic subgroup), forcing suppliers to either match the lowest price for a group of medicines or risk patients and general practitioners choosing a different medicine since patients pay the additional cost if the actual price of a drug is higher than the government subsidy.

PHARMAC encourages development of generics by running competitive tenders for the right of exclusive supply, for a limited period, once a drug's patent expires. PHARMAC also enters into risk sharing, multiproduct deals with drug companies and arrangements which set expenditure caps or rebates, sharing risk with the drug companies over the likely uptake of a particular medicine.7 Substantial savings have been made for several medicines as a result of these policies, 7 with statins now around half the cost that they are in Australia8 and the price of fluoxetine having fallen from $\$ 1.92$ per $20 \mathrm{mg}$ capsule in 1993 to $\$ 0.05$ per capsule in 2004.7 A recent analysis by the Canadian government shows that the price of generic drugs in New Zealand is less than a quarter of the price in Canada and that patented drugs are $20 \%$ cheaper. 9

\section{Effect on drug expenditure and access}

Complete data are not readily available on measures relating to spending and access. However, PHARMAC has made substantial savings, and growth in expenditure has slowed, since it was established in 1993. At the end of PHARMAC's first year, it announced a first year saving of $\$ 3.1 \mathrm{~m}$ against the previous trend and had halved the growth in drug expenditure to around 5\% a year.10 PHARMAC's estimated cumulative savings for the year ending June 2006 were $\$ 1032 \mathrm{~m}$, predicted to rise to $\$ 1250 \mathrm{~m}$ for the year ending June 2008 (fig $1 \underline{\mathbb{}}$ ). 11 New Zealand's Treasury reports that between 1994 and 2008, the community drug budget increased at an average annual rate of $2 \%$ compared with $15 \%$ in the 1980 s. This compares with an overall rise in public health spending over the same period of $7.2 \%$ a year. 12

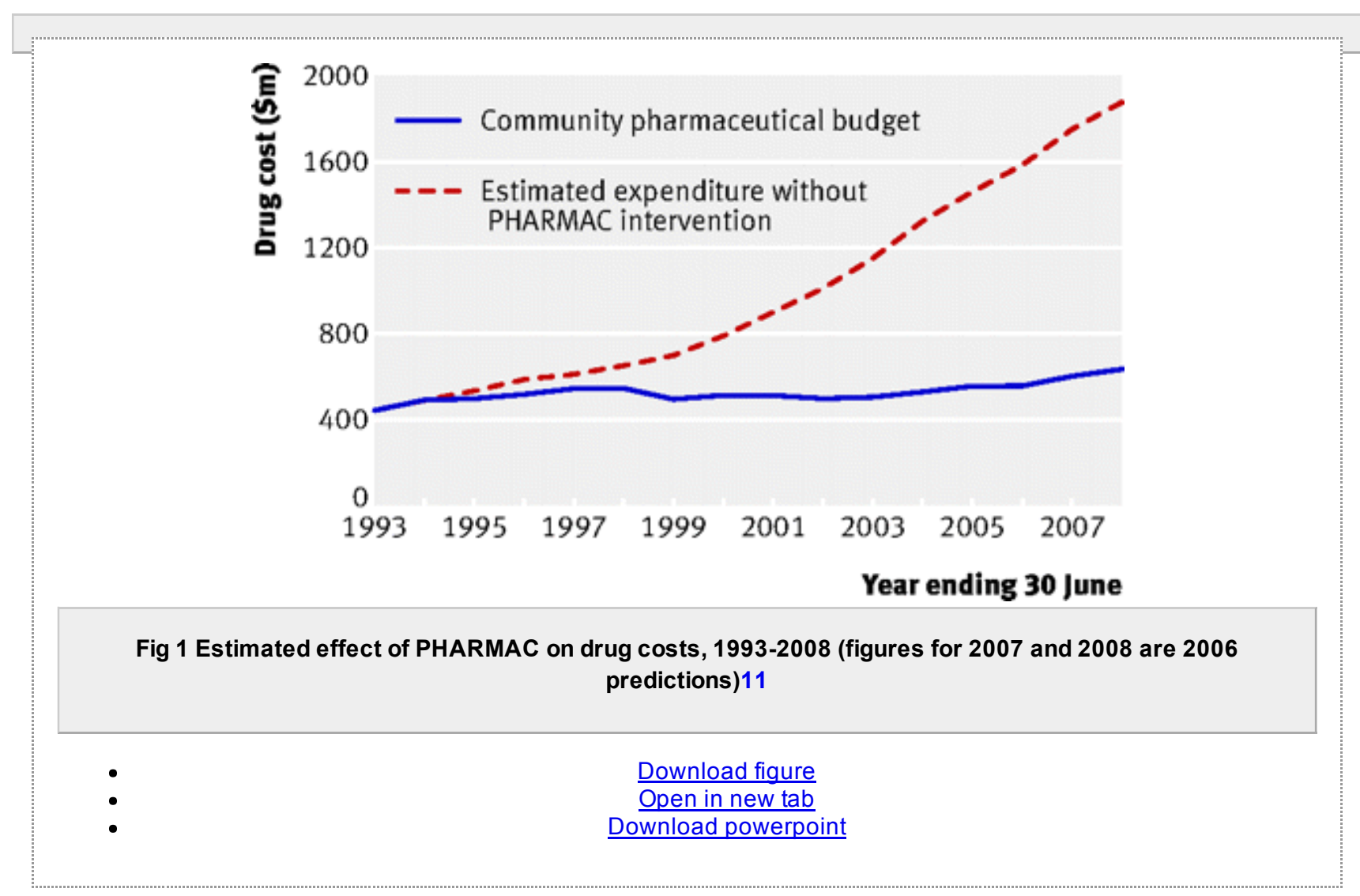

OECD data (fig $2 \underline{\Downarrow}$ ) show that New Zealand's pharmaceutical expenditure as a percentage of total expenditure on health services (public and private) fell after PHARMAC was established in 1993, while such spending rose 


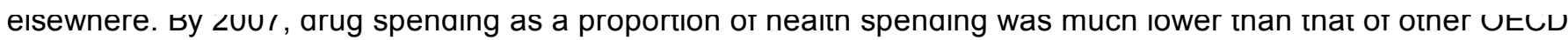
countries.

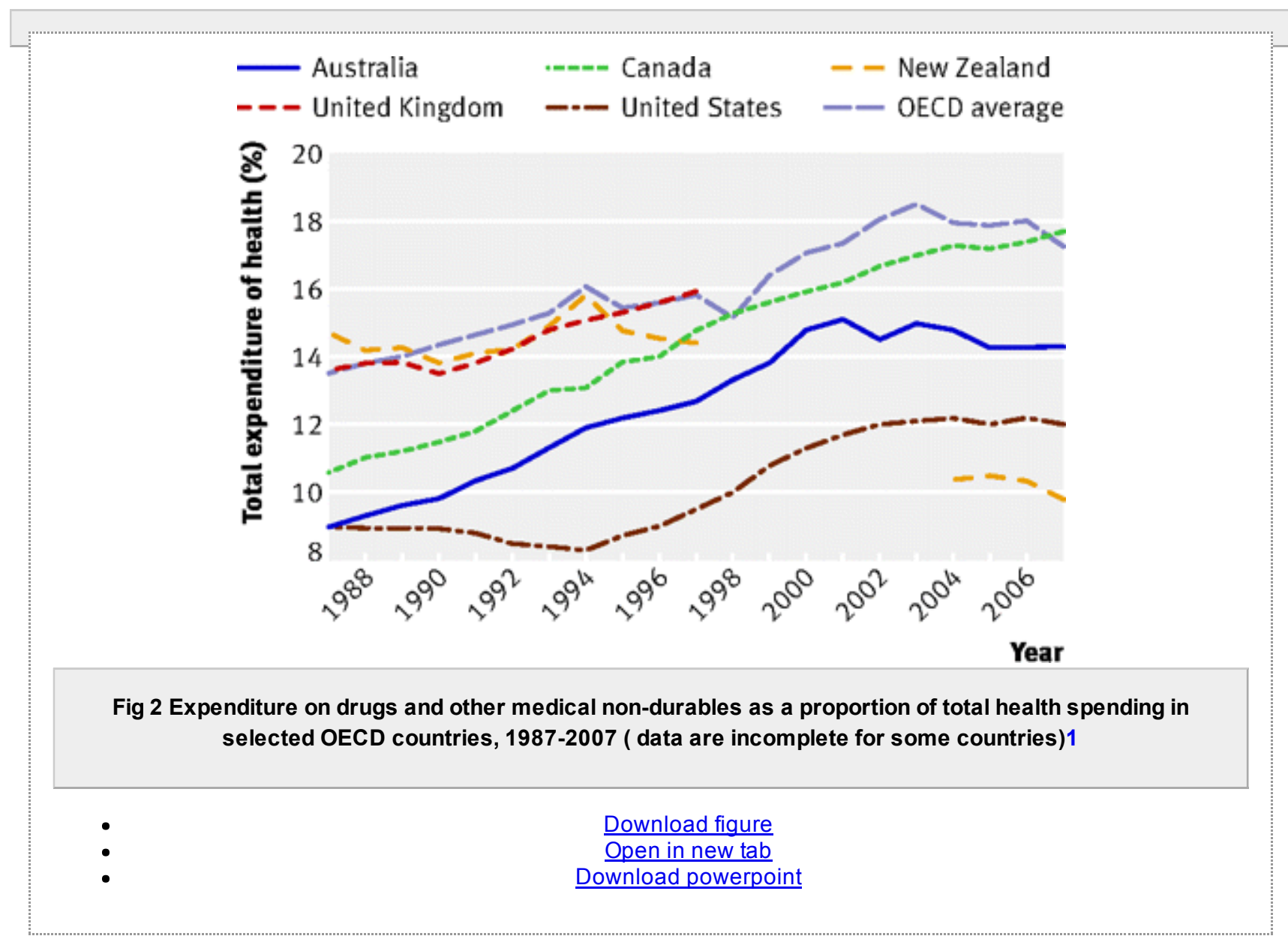

Despite the low rise in drug spending, the number of medicines on the pharmaceutical schedule increased by 188 items between June 1993 and 2007.13 The number of prescriptions has also increased from around 18 million in 1993 to almost 32 million in 2007,13 although a reduction in copayments over the past seven years explains some of this increase. The average cost per prescription in 1993 in New Zealand was $\$ 24.30$, but by 2007, this had fallen, in nominal terms, to $\$ 19.00 .14$

\section{Criticisms}

PHARMAC has been criticised for using anti-competitive strategies to reduce the overall cost of drugs and for the fact that PHARMAC's decisions and contracts relating to subsidised drugs are exempt from New Zealand's Commerce Act (which aims to promote market competition). Examples cited include grouping patented medicines with generics within therapeutic subgroups, thereby eroding intellectual property; tendering for sole supply rights; refusing to list a new drug for subsidy unless it undercuts the price of the existing reference drug; and refusing to include a new drug on the schedule if PHARMAC deems the market sufficiently provided for.15 Such policies, however, could be viewed as essential for managing the drugs market in the face of well known, serious imperfections.16 17 In 1997 and 1998, decisions of the High Court, Court of Appeal, and the Privy Council upheld the legality of PHARMAC's procedures in managing drug expenditure and its exemption from the Commerce Act.10

A second concern is access to clinically effective medicines. PHARMAC's decisions not to fund particular drugs have often been controversial.18 19202122 For example, restrictions meant statins were initially available only for secondary prevention in people at higher risk (on application by a specialist). These restrictions continued into the mid-1990s despite international studies that had begun to show greater effectiveness for patients with lower cholesterol levels.23

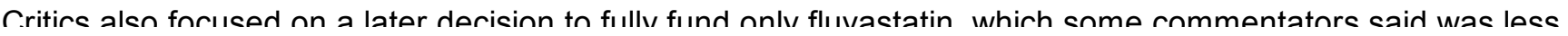


effective than other statins.23 24 Concern was also expressed about repeated changes in the reference priced statin, resulting in patients having to switch medicines, some several times, as simvastatin eventually became available more cheaply after a deal with the manufacturer.23 24 Begg and colleagues argue that the statins saga shows that PHARMAC has focused more on financial imperatives than evidence based medicine and good patient care, and that such switching between drugs is not good for patients. 24

PHARMAC responded to the criticisms by focusing on the high initial costs of statins, stating that wider availability could have cost almost $\$ 200 \mathrm{~m}$ a year $-40 \%$ of the community drug budget. 25 This would have prevented expenditure on drugs for other conditions, including, at that time, atypical antipsychotics for treatment resistant schizophrenia; cyclosporine A and tacrolimus for treatment resistant epilepsy; and treatments for refractory glaucoma.25 26 PHARMAC noted that although fluvastatin might have been less effective in lowering lipids than simvastatin, its lower price made the potential to fund treatment for many more patients "compelling." 25

More broadly, critics focus on whether New Zealanders are missing out on effective medicines that are available in other countries, thus harming their health. In 2007, the Pharmaceutical Industry Taskforce identified several drugs available elsewhere that were restricted in New Zealand (box 2).27 A more recent report has argued that New Zealand has 84 fewer innovative medicines funded than Australia, 28 although PHARMAC says that of the 42 which it has been asked to make a decision on, seven have been funded, 11 have been declined, and the remainder seem to offer little or no benefit over drugs already funded.29

\section{Box 2 Examples of drugs restricted in New Zealand in 2007 but available elsewhere27}

\section{Unfunded}

- Risedronate for osteoporosis and Paget's disease

- Methylphenidate and atomoxetine for attention deficit hyperactivity disorder

- Galantamine for Alzheimer' disease

- Montelukast for asthma

\section{Long delays in access}

- Mycophenolate mofetil for renal transplant patients

- Glatiramer acetate for multiple sclerosis

\section{Restrictions on access}

- Candersartan for congestive heart failure (now subsidised)

- Insulin glargine for diabetes

Several criticisms have also been made about quality of care resulting from PHARMAC decisions. There have been medical concerns about switching patients not only to different brands of medicines but also to different chemicals within the same sub-groups. We have noted the concerns over switching between statins. Another example is the substitution of quinapril, and to a lesser extent cilazapril, for other angiotensin converting enzyme inhibitors in 2002. A retrospective study of 345 patients showed that $30 \%$ did not sustain the initial switch and $11 \%$ of those patients with previously stable blood pressure remained uncontrolled six months after the switch, 30 although a second study found no change in mean blood pressure.31 
slow release morphine and that the generic paracetamol was difficult for some people to swallow because it had no covering film.32 The flu vaccine chosen for sole supply in 2005 was under-strength in one of the three component flu strains, and another company had to step in to supply the vaccine.32 PHARMAC now works with two suppliers for vaccines but notes that sole supply is the norm with all patented medicines.33 Sole supply has similarly been blamed for drug supply problems towards the end of the contract period. 32

\section{Government intervention}

Despite these criticisms, PHARMAC has survived major health system reforms by different governments over the past 16 years, and only twice has government over-ruled its decisions.

The first case was interferon beta for multiple sclerosis. Although the drug was available for private purchase, PHARMAC said it was not cost effective for most patients at $\$ 20000$ per patient a year. After a pledge by the Labour party to fund the drug as part of its successful 1999 general election campaign, the minister of health directed PHARMAC to make it available to a limited number of people judged suitable by a panel of neurologists (this cap was removed in 2002). This action raised questions of both the independence of PHARMAC and the problems of balancing a budget while providing adequate health care.34

In 2006, PHARMAC decided against funding a 12 month trastuzumab (Herceptin) programme for women with the aggressive HER2 positive form of breast cancer, which would have cost an estimated \$25m-\$30m year.35 36 Instead, PHARMAC agreed to fund a nine week course, at an estimated cost of $\$ 5 \mathrm{~m}$, with a further $\$ 3.2 \mathrm{~m}$ to participate in an international trial of a short versus long course of concurrent treatment. At the time, the personal cost to patients wishing to have the full 12 months' treatment was around $\$ 70000.37$

PHARMAC's rationale for this decision related to uncertainties over long term benefits and risks; how best to give the medicine (sequencing and duration); the high overall cost; and the relatively poor value for money of the 12 month course compared with other medicines.36 The decision caused substantial controversy and led to a group of women with breast cancer taking PHARMAC to court. Most of the claims were rejected, but the court ordered PHARMAC to reconsider one decision on procedural grounds, relating to the adequacy of its consultation with interested parties about the 12 month course of treatment.38 Having reconsulted and reconsidered its original decision, PHARMAC still decided not to proceed with the 12 month course. Section 65 of the New Zealand Public Health and Disability Act 2000 meant that the then minister of health was not able to direct PHARMAC to fund the 12 month course, even if he had wished to do so. Following its election in December 2008, the National party-led government announced that it would subsidise the 12 month course directly through the ministry of health, bypassing PHARMAC altogether.39

\section{What can other countries learn?}

The main lesson from PHARMAC for other systems is that it is possible to manage drug spending within a public budget while improving access to subsidised medicines. However, other countries need to consider several factors if they are to learn from PHARMAC's experience.

Firstly, New Zealand has limited its own drug development and manufacturing (and what there is focuses on generics). The government is not as concerned with the economic performance of its drug industry as with the efficiency with which its health budget is used. In other countries, decisions would need to balance economic and health system objectives.

Secondly, PHARMAC is legally bound to keep within a community drug budget, set each year by the minister of health with advice from PHARMAC and the district health boards. Thus it has to take account of the opportunity costs of its decisions (at least with respect to other drugs), rather than merely providing advice or requiring others to implement its decisions as, for example, the National Institute for Health and Clinical Excellence (NICE) does in

England. As a result, PHARMAC has strong incentives to limit prices and obtain better value for money, and the 
budget setting process enables general consideration of the opportunity cost of spending more on drugs against spending on other services every year.7

A third related factor is that PHARMAC is a national agency, setting national priorities and contracts on behalf of all 20 district health boards. This gives it substantial bargaining power in negotiations with drug companies.

A fourth feature is PHARMAC's strong focus on trying to achieve the best outcomes within its funding. There is some evidence that cost effectiveness analysis has more of an effect on drug funding decisions in New Zealand than in the United Kingdom and Australia. For example, of the 10 drugs deemed least cost effective by NICE between 1996 and 2005, all were approved for funding in the UK, six were approved in Australia, and just five in New Zealand.40

Finally, PHARMAC has had an important role in debates on the need to set priorities in health care in New Zealand and has shown how this can be done using rigorous processes. The fact that PHARMAC has only twice been over-ruled by government shows that a focus on explicit priority setting within a budget can work well and that hard decisions can gain support if well justified.

\section{Notes}

Cite this as: BMJ 2010;340:c2441

\section{Footnotes}

- We thank the editors, peer reviewers, and New Zealand reviewers for their comments on drafts of this article.

- Contributors and sources: JC has a background in economics and public policy and has a longstanding interest in health policy, including in priority setting. NM has a background in health services research and health policy, and has advised both the New Zealand Treasury and Ministry of Health on a range of issues, including resource allocation, since 1998. JD works as a research assistant on a variety of health services research projects. JC is guarantor. She supervised the literature search and review, and drafted various versions of the paper. NM helped structure the analysis in the paper and edited and commented in detail on successive drafts. JD was responsible for the literature search and review which provided the sources of information for this paper.

- Competing interests: None declared.

- Provenance and peer review: Not commissioned; externally peer reviewed.

\section{References}

1. $\lrcorner$ Organisation for Economic Cooperation and Development. OECD health data 2009—selected data. http://stats.oecd.org/Index.aspx?DatasetCode=HEALTH

2. $\lrcorner$ Ministry of Health. Health expenditure trends in New Zealand, 1980-2000. Wellington: Ministry of Health, 2002:1-75.

3. JPHARMAC. Introduction to PHARMAC. www. pharmac.govt.nz/2008/12/16/01 PHARM Infsheet INTRO.pdf.

4. $\lrcorner$ PHARMAC. Operatingpolicies and procedures of the pharmaceutical management agency ("PHARMAC"). 2006. http://www. pharmac.govt.nz/2005/12/22/231205.pdf

5. $\lrcorner$ PHARMAC. Prescription for pharmacoeconomic analysis: methods for cost-utility analysis. 2007. www.pharmac.govt.nz/2007/06/19/PFPAFinal.pdf 
6. $\downarrow$ Metcalfe S, Dougherty S, Brougham M, Moodie P. PHARMAC measures savings elsewhere to the health sector. NZ Med J2003;116:U362. Medline

7. $\downarrow$ Grocott R. Applying programme budgeting marginal analysis in the health sector: 12 years of experience. Expert Rev Pharmacoecon Outcomes Res2009;9:181-7. CrossRef Medline

8. $\downarrow$ PHARMAC. Medicines Strategy. 2007. www.pharmac.govt.nz/2009/07/10/Submission\%20on\%20the\%20development \%20of\%20the\%20Medicines\%20Strategy.pdf.

9. $\downarrow$ Patented Medicine Prices Review Board. Non-patented prescription drug prices report: Canadian and foreign price trends. 2006. www.pmprb-cepmb.gc.ca/CMFiles/nppdp-2e38IJV-1162006-9192.pdf.

10. $\lrcorner$ PHARMAC. About PHARMAC: Important events in PHARMAC's history, 2008. www.pharmac.govt.nz/dhbs/AboutPHARMAC/history.

11. $\amalg$ PHARMAC. Annual review 2006. 2006:32. www.pharmac.govt.nz/2006/11/24/ARev06.pdf.

12. $\rfloor$ Treasury. Historical vote health information. 2009. www.treasury.govt.nz/budget/votehistory/health.

13. $\triangle$ PHARMAC. Annual review 2007. 2007:32. www.pharmac.govt.nz/2007/11/21/PHARMAC AR 2007.pdf.

14. $\downarrow$ World Health Organization. World health report 2008. WHO, 2008:1-143.

15. $\downarrow$ Pharmaceutical Research and Manufacturers of America. New Zealand: market access for pharmaceuticals.www.cptech.org/ip/health/phrma/nte-98/nzealand.html.

16. $\downarrow$ Scherer FM. The pharmaceutical industry_prices and progress. N Engl J Med2004;351:927-32. FREE Full Text

17. $\lrcorner$ Docteur E, Paris V. Ensuring efficiency in pharmaceutical expenditures. In: Achieving better value for money in health care. OECD, 2009:101-28.

18. $\downarrow$ Grainger R, Harrison A. TNF inhibitors for inflammatory arthritis in New Zealand. N Z Med J2005;118:U1706. $\underline{\text { Medline }}$

19. $\downarrow$ Gillies J, Brown J, Byrnes C, Farrell A, Graham D. PHARMAC and Ventolin in New Zealand. N Z Med J2005;118.U1616.

20. $\downarrow$ Grocott R, Metcalfe S. Going against the flow: the impact of PHARMAC not funding COX-2 inhibitors for chronic arthritis. N Z Med J2005;118:U1690. ㅆ Medline

21. $\downarrow$ Metcalfe S, Moodie P, Davies A, McNee W, Dougherty S. PHARMAC responds on salbutamol. N Z Med J2005;118:U1644. Medline

22. $\downarrow$ Woolner D. Merck responds to PHARMAC's article on COX-2 inhibitors. N Z Med J2005;118:U1746. Medline

23. $\downarrow$ Ellis C, White H. PHARMAC and the statin debacle. N Z Med J2006;119:U2033. Medline

24. $\downarrow$ Begg E, Sidwell A, Gardiner S, Nicholls G, Scott R. The sorry saga of the statins in New Zealand-pharmacopolitics versus patient care. N Z Med J2003;116:U360. Medline

25. $\downarrow$ Moodie P, Metcalfe S, McNee W. Response from PHARMAC: difficult choices. N Z Med J2003;116(1170):U361. Medline

26. $\downarrow$ Moodie P, Dougherty S, Metcalfe S. PHARMAC and statins-getting the best population health gains. NZ Med J2006;119:U2092. Medline

27. $\downarrow$ New Zealand Pharmaceutical Industry Taskforce. Submission on the Towards a New Zealand Medicines Strategy Consultation Document. 2007. www.rmianz.co.nz/downloads/NZPITsub.pdf.

28. $\lrcorner$ Researched Medicines Industry. The Trans-Tasman Gap Widens. RMI Newsletter2009;24. www.rmianz.co.nz/ezines/Vol24.htm.

29. $\downarrow$ McCormack P, Quigley J, Hansen P. Review of access to high-cost, highly specialised medicines in New Zealand. Wellington: Ministry of Health, 2009.

30. $\downarrow$ Maling T. Finding a better balance between pharmaceutical supply and demand - a medicinal issue. $N Z$ Fam Physician2002;29:3.

31. $\downarrow$ Perkins E, Dovey S, Tilyard M, Boyle K, Penrose, A. A change management strategy to modify ACE-inhibitor prescribing. RNZCGP Research Unit, 1999.

32. $\downarrow$ MacKay P. Is PHARMAC's sole-supply tendering policy harming the health of New Zealanders? N Z Med 
J2005;118:U1433. Medline

33. $\downarrow$ McNee W, Moodie P, Schmitt S, Dick A. PHARMAC's response to Tim Blackmore on the sole supply of influenza vaccine. N Z Med J2005;118:U1601.

34. $\downarrow$ McNaughton $H$, Kayes N, McPherson K. Interferon beta, PHARMAC, and political directives: in the best interests of people with multiple sclerosis? N Z Med J2006;119:U1939. Medline

35. $\downarrow$ Rosevear M. PHARMAC and Herceptin for early-stage breast cancer in New Zealand: Herceptin or deception? N Z Med J2006;119:U2014. Medline

36. $\downarrow$ Metcalfe S, Evans J. PHARMAC responds on Herceptin assumptions and decisions. N Z Med J2007;120:U2692. Medline

37. $\downarrow$ Graham K. Herceptin, Pharmac and the New Zealand District Health Boards: keeping abreast of the Code of Health and Disability Services Consumers' Rights? J Law Med2008;16:103-8. Medline

38. $\downarrow$ High Court of New Zealand. Walsh v PHARMAC. Wellington Registry, 2008:1-74. www.pharmac.govt.nz/2008/04/02/090408.pdf.

39. $\downarrow$ Tait M. Govt dodges Pharmac to fund full Herceptin courses. New Zealand Herald2008 Dec 10. www.nzherald.co.nz/politics/news/article.cfm?c id=280\&objectid=10547373.

40. $\downarrow$ Raftery JP. Paying for costly pharmaceuticals: regulation of new drugs in Australia, England and New Zealand. Med $J$ Austr2008;188:26-8.

- $Y$ Tweet

- f Like 2

- $G+1\}$

\section{Article tools}

\section{3 responses}

- שேRespond to this article

- BPrint

- Alerts \& updates

\section{Article alerts}

Please note: your email address is provided to the journal, which may use this information for marketing purposes.

\section{Log in or register:}

\section{Username * \\ Password * \\ Log in}

$\underline{\text { Register for alerts }}$

(1) If you have registered for alerts, you should use your registered email address as your username

- OCitation tools

\section{Download this article to citation manager}

Cumming Jacqueline, Mays Nicholas, Daubé Jacob. How New Zealand has contained expenditure on drugs BMJ 2010; 340 :c2441 